\title{
Quality loss of surroundings in urban places
}

\author{
L. Benyounes-Ferahta \\ Ecole Polytechnique d'Architecture et d'Urbanisme, Algeria
}

\begin{abstract}
Today, quality of life is a major issue, since the physical and aesthetic degradation of the built environment is manifested by a difficulty reading our own city, and lack of sense of belonging. Thus, quality of life is currently a major expectation, to claim time, even if it is perceived on spatial scales and temporalities, which differ from the user to the different actors of the urban landscape. This raises the question of how to explore the causes of the lack of quality of our urban environment and the relationships between the quality of the built environment and the quality of life. It refers in particular to the need for further reflection on the mechanisms that govern the production of urban space, which passes through the consideration of the relationship between urban structure and social and economic functioning of the city, as well as with eco systemic components. Similarly, the sustainability paradigm of urban structures, environmental and socio-economic are closely linked and must be addressed in a transverse vision by any sustainable urban development policy, while integrating the different logics of urban actors. This finally implies that the update target parameters must establish spatial and environmental schemes that promote quality of life and urbanity. It reflects, in particular, the possibility of developing a system of indicators to conduct an evaluation of the quality of the urban landscape, to finally lay the foundations of a process of urban renewal that guarantees the quality of life and urbanity.

Keywords: quality of life, quality of the built environment, sustainability, urbanity.
\end{abstract}

\section{Introduction}

Urban quality has been of major interest since the environmental and esthetical decay of surroundings occurred. People have difficulties in perceiving their own city, to have a feeling of belonging and individuals cannot identify to it (Levy and Spigai [1]). Currently, qualitative concerns are at the center of debates and there 
are many references to this subject. It has caught the attention of researchers and concerned people. It is difficult to outline the territories of intervention.

Therefore, urban quality is a current issue, even if it is perceived through spatial scales and different temporalities, from user to economical actor, politician and technician.

Indeed, the urban problem is currently more related to decreasing quality than to quantity. This tends to cause more urban and social conflicts and to accelerate the level of decay of built and natural surroundings.

The issues and consequences of urban sprawl on the quality of built and natural environment urge us to make urban system dynamical subsystems emerge. These systems are components facing emerging urban problems.

Moreover, the context is constantly in mutation. It includes new scales and encourages the emergence of new concepts. It requires new evaluation and implementation means in the political framework of a renewed city.

Precisely, the enlightening of approaches related to an elaborated process of urban requalification and evaluation methods of urban quality is absolutely necessary.

\section{Structural causes of urban environment decay}

The noticed assessment of decay in our urban environment is added to the failure of urban development control and deficiency about city knowledge and knowhow. The major signs are:

- Continuities disappeared: functions organization making the neighborhoods animation, depends on them,

- Lack of clarity in hierarchy of spaces that makes the global structure readable and gives a specific sense to places,

- Unbalance in built and non built spaces that leads to a lack of coherence of urban form.

Urban sprawl, the emergence of urban spatial organization new forms, financial costs and context unbalance are real issues for introducing a requalification process in our environment, therefore our quality of life (Barecelo [2]). It means to get consciousness by preserving the urban landscape that needs to be updated through target parameters. These are useful for spatial and environmental devices. They could provide, at the urban scale, quality of built and natural context, quality of life and promote a real urbanity (Devilliers [3]). Also, we tried to answer the serious question: how could we explore causes of loss of quality in our urban environment as well as relations between quality of built environment and quality of life?

As a hypothesis, we stated that deficiency levels in creating a coherent urban landscape is explained by weak management tools and particularly by concealing urban composition scale in the planning system (Parain [4]). It is confirmed by concealing the environmental dimension and its consequences on future developments, particularly when local specificities are not taken in account as well as community dimensions. 
Today, studying urban landscape quality sends us towards sustainability. We are supposed to take in account connections with urban structure, city financial functioning and also eco-systemic local and global components (Filion [5]). This means that urban structures, the process of urban requalification, and environmental and socio economical components are tightly linked. They must be studied through a transversal vision by any urban management policies. These must be integrated into the different territorial logics, spatial scales and concerned actor systems.

This means that thinking has to focus on the urban landscape and production in order to undertake actions in the view of its requalification, while aiming towards environmental balance (Newman [6]). In this perspective, urban requalification questions urban space through urban composition. Of course it will be based on sustainable development principles because of their qualitative processes and complementary roles in this process (Levy [7]).

\section{Methodology}

We propose a methodology that will be able to reveal the question of urban issues in a context where urban sprawl appears through emergence of new territories which have new, morphological, thematic and scaling characteristics (Bochet [8], Batty and Longley [9]). In this respect, we ask for transdisciplinarity of the urban object related to its semantic complexity, systemic aspects where the different approaches - morphological, landscape and environmental - interact.

The aims of this approach are:

- Hierarchy of different spatial structures,

- Make out their connections,

- Classify them according to a generative way for producing urban form.

The approach requires working at several scales and is based on a principle: urban phenomenon responds to laws and regulations which come from economical functioning and spatial structures. This thinking has been holding a dynamic aspect which defines situations and their evolution. Morphological approaches of urban layouts help to set up relations to quality, multiplicity and relativity of points of view as well as explanation ways for urban quality in order to show up its complex character.

This methodological process develops research attitude around implementation conditions of urban requalification in territories which need a particular concern and an adapted operative mode. This process aims also to give an account about urban issues.

Therefore we rely on the analysis of the urban Fringe of Boukhadra in Annaba, showing its resulting structural and functional deficiencies as well as social, economical and environmental unbalance.

This analysis will indeed contribute to globally undertaking the multidimensional character of qualitative problematic. Interactions between key components will be studied in a systemic approach. Also mechanisms of urban systems and subsystems will be taken in account at different spatial, temporal, 
environmental and socio economical scales in order to emphasize quality of life, which confirms the quality of the built context.

\section{Methods for a permanent quality of place}

When urban transformations are added to deficient quality of urban environment, new thematics could emerge (Bochet and Cunha [10]). They need new tools and new methods for interventions. Other processes should promise permanent quality of life in places. It means that intervention strategies must be located in emergent territories in peripheries. Sustainable development has to be a framework. Therefore, urban composition method makes the parameters of spatial quality in order to set an evaluation model of urban environment quality.

\subsection{Evaluation draft for quality of place}

The scheme below helps for the restitution of evaluation steps.

Empirical verification:

- To make a research draft,

- Empirical verification through selected concepts,

- Proposition of a generic work: "specifications".

Our method consists of:

1. Bringing out the choice criteria of selected methods to evaluate AFOM, SWOT and AMC,

2. Defining their content and goals,

3. Highlighting their role in evaluation process and particularly the combination pertinence.

Now we intend to build our quality evaluation. It will be done according to a research draft that respects the following key steps.

\subsubsection{Key steps of evaluation draft}

Evaluation draft steps that we have made out are structured following methods: Urban composition -AFOM-SWOT-AMC, with this logic:

\section{Step 1: Identification of strategic issues that have priority}

In order to identify these issues, the AFOM method helps us make out a complete list of assets, weaknesses, opportunities and threats. This list has been evolving according to each concept that is related to urban fringes features for aiming global issues.

SWOT method has been leaning on the list as a source that helps make a deeper diagnosis. This method will be explained in a grid where inner and outer forces are transversal and related to concepts show urban fringes features. This crossing has been making out strategic issues that concern the specific site. 


\section{Step 2: Building the evaluation board of quality that is coming out of urban composition parameters}

This is about making quality parameters from the Urban Composition method made before and leading to a first grid:

- Grid No. 1: global evaluation of quality that proposes parameters for urban and environmental quality. It comes out from the synthesis of many combinations of urban environment features given by urban composition method. This grid a conclusion about patrimonial value of urban landscape. Also it helps going from an identification and observation situation and from a subjective observation to a comprehension of urban fringes features cited and conceptualized in (Part 1): the 4 concepts, density, scale, fragmentation and urbanity.

- These concepts will be useful as a basis in order to go from a global grid No. 1 to a more synthetic grid No. 2 .

- Grid No. 2 (synthetic): For an objective/qualitative evaluation which could be made by a limited number of target indicators in order to facilitate the evaluation. It holds the 5 quality criteria: Structural; Functional; Morphological; Environmental; Socio-economical. These will be useful as reference for the quality evaluation through 4 identified concepts.

- Grid No. 3: from grids 1 and 2 together:

o The 4 concepts and the 5 criteria are integrated.

- Each criterion is divided in 2 indicators that will help design a system of 40 indicators for expressing situations: dynamic/static; perceived/lived; subjective/objective; qualitative/quantitative.

$\circ$ The 20 indexes coming from aggregation of matching indicators of quality, indexed of: coherence-balance; (compacité)-variety; permanence-continuity; readability-(reticulation).

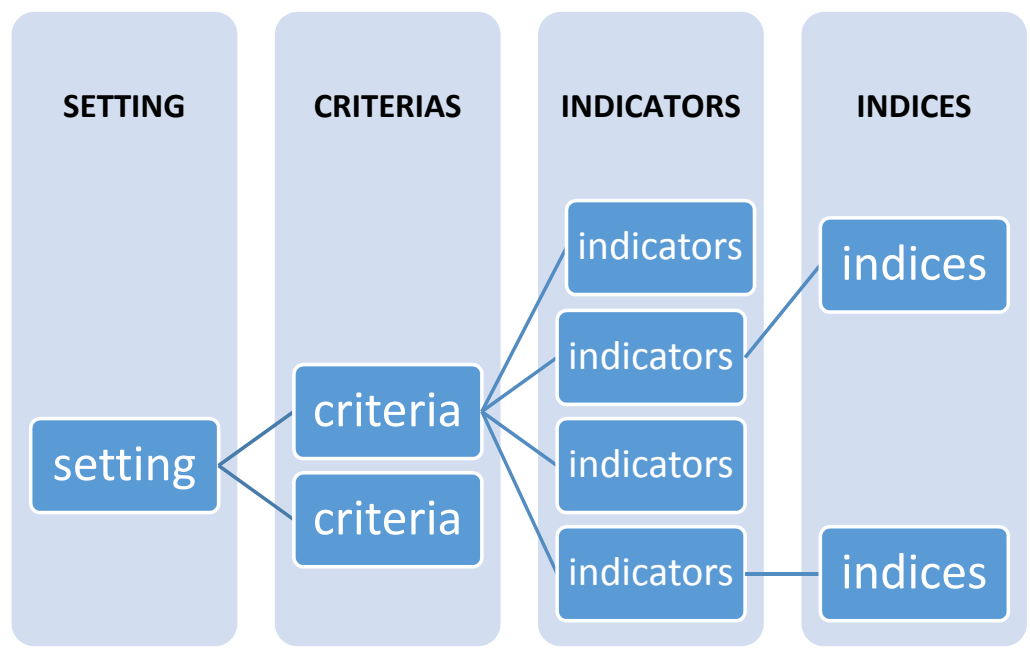

Figure 1: Hierarchical system for evaluating quality. 
The decision about defining the issues and criterion aims to clarify ambiguity about the used terminology in order to pursue the sequence of selected methods.

\section{Step 3: Quality evaluation (Hatchuel and Poquet [11])}

The AMC method proceeds by these following steps:

1. Using strategic issues brought out by SWOT.

2. Taking in account the 4 selected concepts - Density; Fragmentation; Scale; Urbanity - through which the evaluation will be made.

3. The 4 concepts that will be a frame for evaluation are submitted respectively to the 5 criterions of urban quality that were defined by the urban composition method: Morphological; Functional; Structural; Socio/Economical; Environmental.

4. These measured indicators are confronted to reference values to be graded.

The first period will be conducted by specialists:

- The grading allocated by specialists is spread univocally upon a common scaling. It helps get critical limits and orient programming. Regards our evaluation needs, we have fixed a 0 to 3 scaling in order to simplify it.

- Specialists should proceed to evaluation.

- Measuring the indicators values and units in $\mathrm{m}^{2}, \mathrm{ml}, \%, \mathrm{Ha}$ (Duport [12]).

- We compare these measures referentially.

- Correspondence grid between attributed grade and conformity level compared with reference system:

\begin{tabular}{|ll|}
\hline Note & References compliance level \\
\hline $\mathbf{0}$ & Non-compliant \\
\hline 1 & Poor \\
\hline 2 & Moderately compliant \\
\hline 3 & Compliant \\
\hline
\end{tabular}

The second period should be conducted by consultation groups after having attributed the balance ratio to each criterion. These ratios are the result of a "MultiAgents" grid made with consulting groups in order to evaluate the consensus degree compared with given interest to each criterion. The given balance ratio for each indicator goes from 1 to 3 (Schärlig [13]).

1. Index values, once acquired this way, help build radar diagrams where each branch corresponds to the index value:

$$
\text { Value index }=\frac{\Sigma \text { note of weighted indicators }}{\Sigma \text { weights }=9}
$$


2. The number of branches of radar diagram corresponds to the 5 indexes taken into account compared to the 4 concepts which are a frame for our evaluation.

\section{Step 4: Analysis of results by radar diagrams}

Now that our evaluation has reached this step, we are able to check diagram results against POS values in order to conclude the degree of including different quality criterion.

The analysis possibilities are:

a) Analysis of quality according to indicators: mark graphic fixed in 40 (barres) gives total vision and is useful for the next step.

b) Analysis of quality according to indexes: radar diagram fixed in 20 branches.

c) Analysis of concepts: radar diagram fixed in 4 branches, is useful for the next step.

d) Analysis according to criterion: radar diagram in 5 branches is useful for the next step.

Each graded branch of graphic/radar diagram is matched with an index that will help present the results and analyze them. It will play the role of:

- Indicating the including level of quality (linked to index) by up-to-date urbanism tools. We will also include the first aspects in order to qualify the context.

- To give an account of quality of context related to selected concept and according to included spatial scale.

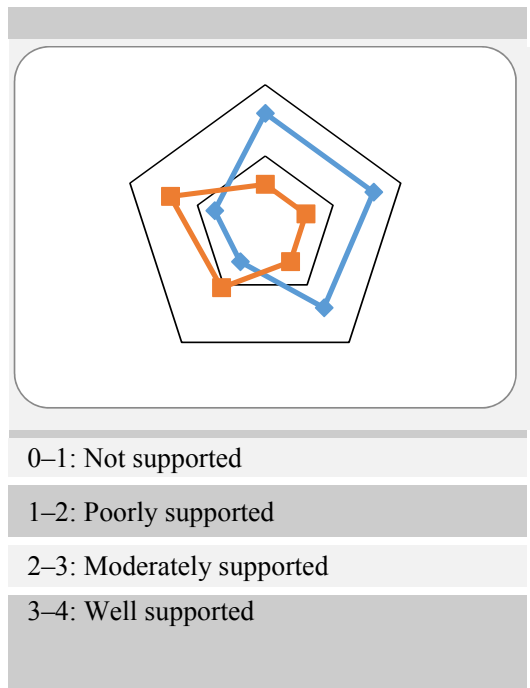

Radar diagram can be broken at all spatial scales of the living environment

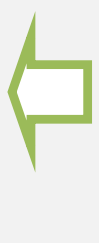

Grid giving the scale of values, which reflects the level of support quality decision by the planning instruments. It refers to the values given by the national or international standards for each indicator considered and allows to compare the values on the site, given by the POS or collected in situ.

Figure 2: Diagram of including level of quality by urbanism tools. 
The goal of this process is to end up with a synthesis that leads to results which help to create a "Sustainable Urban Requalification Process".

\section{Step 5: Proposing an action program}

The next step exposes how to go to an action program that prefers priority principle. That means: action which concretizes expectations more influenced by audit.

This means that quality analysis results have been taken in account in the previous step. Each deficient element shows an action priority. It asks for the formulation of recommendation of actions to be done according to a real stepby-step process. It will aim at the following spatial scales and precise planning fields.

a) Making an action plan: evaluate according to RIF/cost method i.Phasing.

b) Deciding about reference terms that are visualized as reference schemes in order to spatialize.

c) Making the policies rules of urbanism tools aiming projects orientation.

d) Helping decision making.

\subsection{Synthesis}

After this development we have enlightened a requalification strategy and its basis. Its major role in urban renewal process has revealed its different declensions. Among them, there is the urban revalorization and re composition. This asks for urban fringes registration in a sustainable development perspective and proposes the urban composition as privileged tool of urban requalification. Consequently, combination of urban composition tools and sustainable development tools led to quality of living place evaluation.

Table 1: Synthesis of evaluation draft for living place quality, according to new prerogatives of urban composition.

\begin{tabular}{|l|l|l|l|}
\hline Stage & Method & Scope & Content \\
\hline $\mathbf{1 .}$ & AFOM/SWOT & $\begin{array}{l}\text { Diagnostic SWOT analysis } \\
\text { for strategic urbanization }\end{array}$ & $\begin{array}{l}\text { Formulation of the issues and } \\
\text { specific local objectives to the } \\
\text { analysis area }\end{array}$ \\
\hline $\mathbf{2 .}$ & Urban design & $\begin{array}{l}\text { Construction method of } \\
\text { evaluation contextualized } \\
\text { grid }\end{array}$ & $\begin{array}{l}\text { The grid is linked to the objectives } \\
\text { from which it provides: criteria, } \\
\text { indices, indicators }\end{array}$ \\
\hline $\mathbf{3 .}$ & AMC & Evaluation method & $\begin{array}{l}\text { Design of: } \\
\text { - Barème Rating } \\
\text { - A rating from repository } \\
\text { - Weighting system Requirements: } \\
\text {-System of aggregation }\end{array}$ \\
\hline $\mathbf{4 .}$ & Radar diagrams & $\begin{array}{l}\text { Results representation } \\
\text { method }\end{array}$ & $\begin{array}{l}\text { This reflects the level of support for } \\
\text { each parameter by planning } \\
\text { instruments in force }\end{array}$ \\
\hline $\mathbf{5 .}$ & ACTION PLAN & & \\
\hline
\end{tabular}




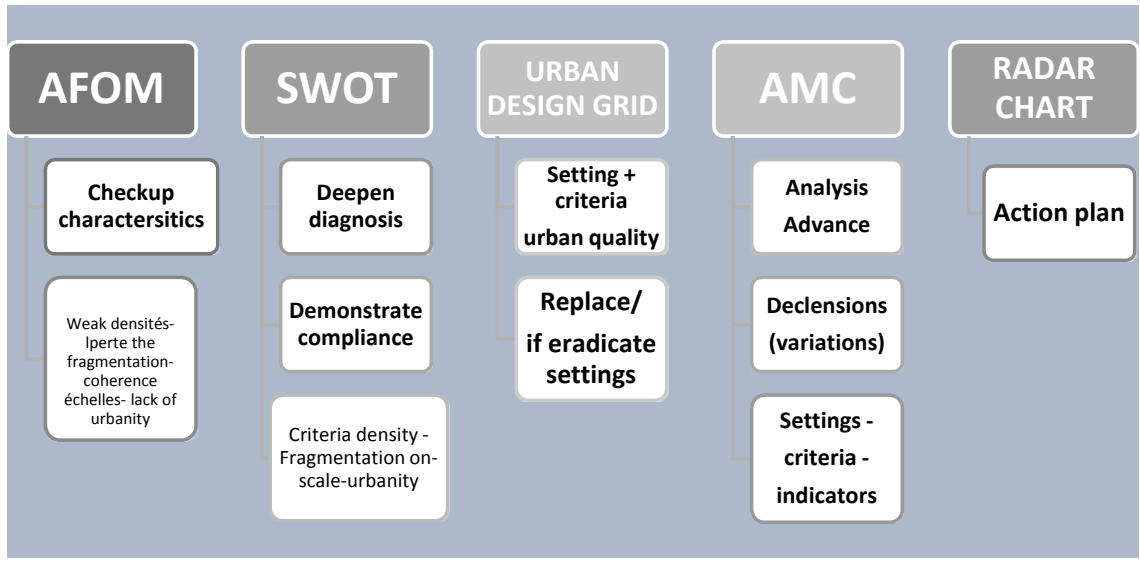

Figure 3: Synthesis of the methodology of the evaluation of living place quality.

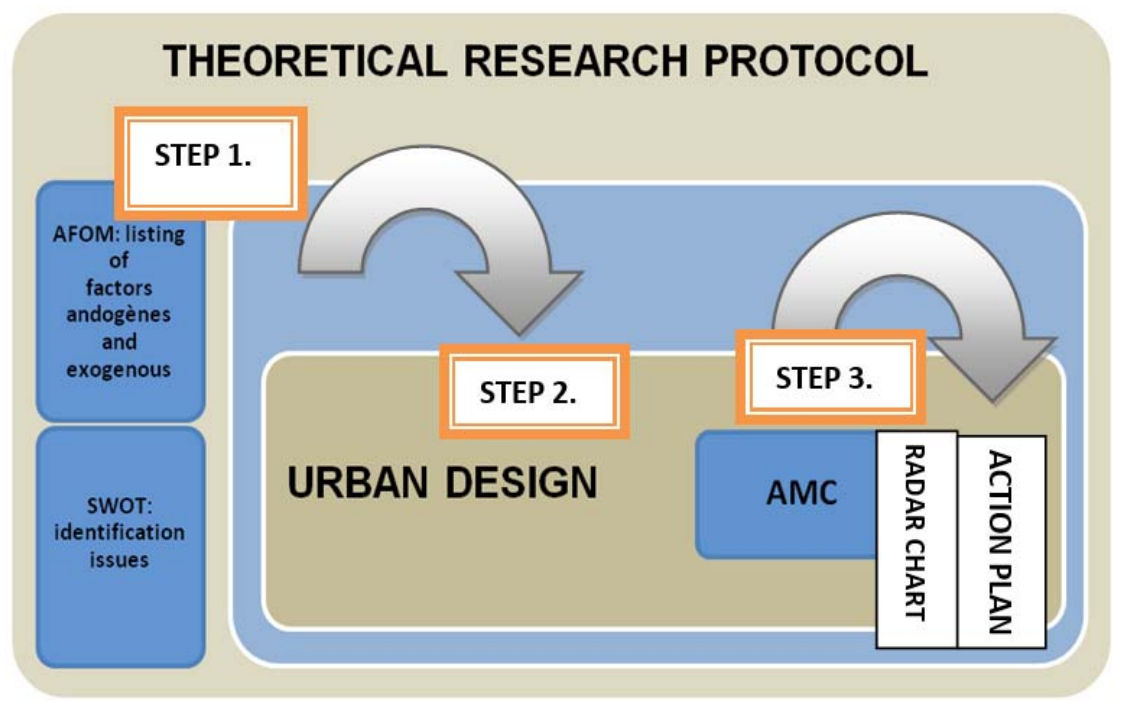

Figure 4: Theoretical research draft.

\section{Conclusion}

This approach, aiming to define the reasons of lack of quality in our urban environment and relations between build space quality and living quality, helped us identify deficiency levels of built space production. It raises particularly the problematic of tools weakness and moreover the absence of scale in urban composition in planning system. It questions emergent urban territories in periphery, about the necessity of their place in an environmental approach, to cure 
ignored local identities. It leads us to a deeper thinking about production mechanisms of urban environment in order to undertake actions for requalification that would be supported by sustainable development principles.

Our searches that aim to promote the living place quality helped us identify the quality issues. At last, the results of this research have demonstrated that the concept of quality could be presented through interesting aspects. The appreciation and the evaluation of these aspects depend on the used referential system. In another hand, they revealed that today the concept of quality is strongly related to environment. Then it becomes necessary to introduce it in a sustainable development logic that suggests taking new parameters in account.

Also it has enlightened the multiplicity of dimensions comprised by quality concept. It affirmed again the necessity of a systemic approach that has been established by sustainable development strategy and it has pointed out vision of indicators method.

We emphasize on ability of urban composition to federate the themes related to the sites. We emphasize also on connection between different urban dimensions and we maintain new prerogatives given by its place in sustainable development logic.

Through our elaborated device we have demonstrated that softer urban strategies, defined in a middle level, appear more relevant for the emergence of a harmonization process. This device has revealed that when we go from planning to implement actions, the result is necessary but complex. Therefore the urban prerogatives at different scales of territory are not improved by the same logics. This situation has generated a governance crisis.

The device has also showed the necessity of dynamic methods for values creation while respecting the caution principles of balance respect. It showed the success of a method that can propose modernity through new conceptual and methodological tools. The presence of this process in a sustainable development vision comes from an indicators system introduced in order to be a reference for the evaluation of urban and environmental quality. It is also a basis for multi criterion decision making. Emerging results from the methodological part are meant to elaborate analysis and evaluation of living place quality tools.

\section{References}

[1] Levy A., Spigai V., La qualité de la forme urbaine. Problématique et enjeux, IFU, Paris, 2001.

[2] Barecelo M., Les indicateurs de l'étalement urbain et du développement durable en milieu métropolitain, le cas de Montréal. 1999.

[3] Devilliers Ch., De la logique de secteurs au projet urbain, Villes en parallèle, no. 12-13. Paris, 1996.

[4] Parain C., L'articulation des échelles de l'espace et du temps dans la conception urbanistique contemporaine, Thèse de Doctorat, 2005.

[5] Filion P., Towards smart growth? The difficult implementation of alternatives to urban dispersion, Canadian Journal of Urban Research, Volume 1, 2003. 
[6] Newman, P., Sustainability and cities: extending the metabolism model, Landscape and Urban Planning, no. 44, 1999.

[7] Levy A., La composition urbaine, un savoir faire en crise, in Vers un nouvel urbanisme, La documentation française. Paris, 1996.

[8] Bochet, B., Morphologie urbaine et développement durable: transformations urbaines et régulation de l'étalement, In Da Cunha et al., Enjeux du développement urbain durable. Transformations urbaines, gestion des ressources et régulation urbaine, PPUR, Lausanne, 2005.

[9] Batty M., Longley P.A., Fractal Cities: A Geometry of Form and Function, Ed.: Technique et Documentation, Paris, 2000.

[10] Bochet B., DA Cunha A., Métropolisation, forme urbaine et développement durable: aménagement des villes et stratégies environnementales, In Cunha A \& Ruegg J, Développement durable et aménagement du territoire, PPUR, Lausanne, 2003.

[11] Hatchuel G. \& Poquet G., Indicateurs sur la qualité de vie urbaine et sur l'environnement. Cahier de Recherche No. 36. CREDOC, Paris, 1992.

[12] Duport, L. T. R., Indicateurs et tableaux de bord de l'environnement urbain, 1998.

[13] Schärlig, Décider sur plusieurs critères. Panorama de l'aide à la décision multicritère, Presses romandes universitaires, Lausanne, 1985. 